\title{
Análise do processo de ocupação da unidade geomorfológica restinga no bairro do Recife Antigo - Pernambuco
}

\author{
Analysis of the geomorphological unit sandbank occupation process in the neighborhood of \\ Recife Antigo - Pernambuco
}

\author{
Santos $^{1}$, L. D. J.; Lima², E. M.; Cabral ${ }^{3}$, C. J.; Silva ${ }^{4}$, O. G.; Correa ${ }^{5}$, A. C. B. \\ leandrodiomerio@hotmail.com;
}

\begin{abstract}
Resumo
O Recife iniciou seu processo de ocupação no XVI com o povoamento da unidade geomorfológica restinga. Nesse contexto, o trabalho tem como objetivo primordial o estudo do processo de ocupação do bairro do Recife Antigo, o qual tem seu sítio urbano assentado na restinga. A pesquisa vem a contribuir para o entendimento do desenvolvimento do bairro e a modificação da dinâmica natural presente na área. $\mathrm{O}$ trabalho foi realizado através do estudo de material histórico de Pernambuco para verificar o quanto à área foi urbanizada. Posteriormente, com a seleção de imagens da restinga ao longo dos anos, foi realizada uma relação com a morfodinâmica da unidade restinga. Nos séculos XVI e XVII a ocupação foi se intensificando a medida que o comércio aumentou e surgiu a necessidade de mais espaço para a urbanização. Assim, começaram os aterros e as construções de cunho mais intenso na restinga e nos demais séculos houve mudanças bruscas tendo a dinâmica da restinga sido alterada para de uma ilha fluvial.
\end{abstract}

Palavras-chave: Restinga. Recife Antigo. Keywords: Sandbank. Recife Antigo. Morphodynamics.

\begin{abstract}
Recife began its occupation process in the sixteenth to the settlement of the geomorphological unit sandbank. In this context, the work has as main objective the study of the occupation of the neighborhood of Recife Antigo process, which has its urban site sitting on sandbank. The research is to contribute to the understanding of the development of the neighborhood and the modification of the natural dynamics present in the area. The study was conducted through the Pernambuco of historical material study to see how the area was urbanized. Later, with the selection of sandbank images over the years, a relationship with the morphodynamic unit sandbank was held. In the sixteenth and seventeenth centuries the occupation was intensified to as trade increased and the need arose for more space for urbanization. Thus began the landfills and the more intense nature of buildings in the sandbanks and other centuries there were sudden changes with the dynamics of the sandbank been changed to a river island.
\end{abstract} Morfodinâmica.

\section{INTRODUÇÃO}

Uma restinga caracteriza-se como barreira/barra ou cordão litorâneo, formadas por faixas arenosas ou de cascalho depositadas paralelamente à praia que se alongam tendo um ponto de apoio em cabos e saliências do litoral e que se localiza acima do nível da maré alta e de idade holocênica, tendo origem a partir da última regressão marinha (SANTOS, 2013). A ocupação da restinga do Recife iniciou no século XVI pelos portugueses por ser útil como defesa contra invasores e um porto natural constituído por arrecifes de arenito. Logo, devido ao fluxo de mercadorias e pessoas surge um pequeno povoado perto do porto, no qual foi chamado de Recife. A configuração urbana

\footnotetext{
${ }^{l}$ Leandro Diomério João dos Santos, Grupo de Estudos do Quaternário do Nordeste do Brasil, UFPE, Recife-PE, Brasil.

${ }^{2}$ Évio Marcos de Lima, Grupo de Estudos do Quaternário do Nordeste do Brasil, UFPE, Recife-PE, Brasil.

${ }^{3}$ Cládio José Cabral, Grupo de Estudos do Quaternário do Nordeste do Brasil, UFPE, Recife-PE, Brasil.

${ }^{4}$ Osvaldo Girão da Silva, Departamento de Ciências Geográficas / Grupo de Estudos do Quaternário do Nordeste do Brasil, UFPE, Recife-PE, Brasil.

${ }^{5}$ Antonio Carlos de Barros Correa, Departamento de Ciências Geográficas / Grupo de Estudos do Quaternário do Nordeste do Brasil, UFPE, Recife-PE, Brasil.
} 
da povoação é verificada através da forma estreita da restinga. As moradias do Povo do Arrecife localizavam-se na ponta do istmo, o qual compreendia sua extensão iniciada em Olinda, por aproximadamente sete quilômetros, e por não mais que meio quilômetro de largura, entre o curso final do Rio Capibaribe, do Beberibe e o mar. A justificativa do assentamento era em decorrência das atividades comerciais ligadas a venda de açúcar e pau-brasil. Além da compra de mercadorias importadas para os portugueses mais abastados de riqueza residentes em Olinda.

No século XVI, especificamente até 1609 , a restinga teve suas características da dinâmica morfológica conservadas, visto a intervenção antropogênica não tinha sido intensa a ponto de mudar a evolução natural da mesma. Fato esse consumado pela observação de iconografias do século onde vai retratar a permanência de uma estreita faixa arenosa longitudinal saindo de Olinda em direção ao Sul. Com presença de poucos empreendimentos urbanos, sendo estes as pequenas construções na sua extremidade onde estaria o povoado do Recife, os ancoradouros identificados pelas ancoras e o forte de São José no meio da restinga que detinha a função de segurança e controle marítimo.

A partir da invasão da Holanda em Recife, no século XVII, a disposição da Companhia das Índias Ocidentais intensifica a povoação levando a capitania de Pernambucana a ganhar um aspecto mais urbano. Nesse contexto ocorre uma expansão para o interior do continente numa direção leste a oeste, frisando que os holandeses procuram melhorar as condições urbanas presentes por questão de necessidade em melhor escoar o produto cana de açúcar da zona da mata para o porto do Recife. Isso se faz presente através de Maurício de Nassau, em 1637, no qual ocorreram as primeiras benfeitorias urbanísticas no Recife com a implementação do primeiro plano urbanístico da cidade.

O Recife teve uma modernização no século XIX gerado por causa do aumento do capital dos proprietários e comerciantes, do resultado da subida do preço do açúcar, algodão e couro no mercado mundial, (LOUREIRO e AMORIM, 2000). Este evidencia ainda que a vida urbana é estimulada originando um crescimento da população de aproximadamente 46.000 habitantes no ano de 1837, para o valor de 116.000, em 1872, fato este evidenciado por intermédio do Primeiro Recenseamento da População Geral do Império. No final do século XIX ocorre uma estagnação populacional tendo a quantidade de pessoas ter caído para 111.000 em 1890 e depois cresceu para 115.000 nos de 1900, (ANDRADE, 1979).

No século XX houve modificações significativas no Bairro do Recife Antigo e o documento cartográfico de destaque na representação da estrutura urbana do Recife no início deste período seria o mapa de 1906 denominando Planta da Cidade do Recife de Menezes (1988). A restinga é uma unidade geomorfológica de pequena extensão territorial tendo sua origem na confluência da morfodinâmica dos agentes marinhos e fluviais. A forma é plana a levemente ondulada composta de uma camada extensa de areia indo de consolidada mais ao centro a não consolidada nas áreas de 
borda. Tem altitude baixa e detém certa instabilidade morfológica, por esta mudar seu estado fisiógrafo de acordo com as condições ambientais presentes, ou seja, é um relevo com uma dinâmica que pode crescer ou diminuir de tamanho dependendo dos condicionantes marinhos e fluviais.

Geomorfologicamente, a área se encontra inserida na planície fluviomarinha do Recife, a qual é constituída, de acordo com a gênese (agradação ou denudação) e a morfologia, por colinas, planícies, terraços e morfologias costeiras, (ASSIS, 2001).

\section{METODOLOGIA}

Inicialmente foi delimitado a área de estudo que está na parte Centro-Leste da cidade do Recife, delimitada pelas coordenadas geográficas $08^{\circ} 02^{\prime} 38^{\prime \prime}$ e $08^{\circ} 04^{\prime} 02^{\prime \prime}$ de latitude Sul do paralelo Equador e 3452'29” e 3452'04” Oeste do meridiano de Greenwich (FIGURA 01). A área de pesquisa perfaz aproximadamente 4,678 km2 e tem limites circunvizinhos a Leste com Oceano Atlântico Sul, a Oeste com os bairros Santo Amaro e Santo Antônio, a Norte com o município de Olinda e a Sul com os bairros Brasília Teimosa e São José.

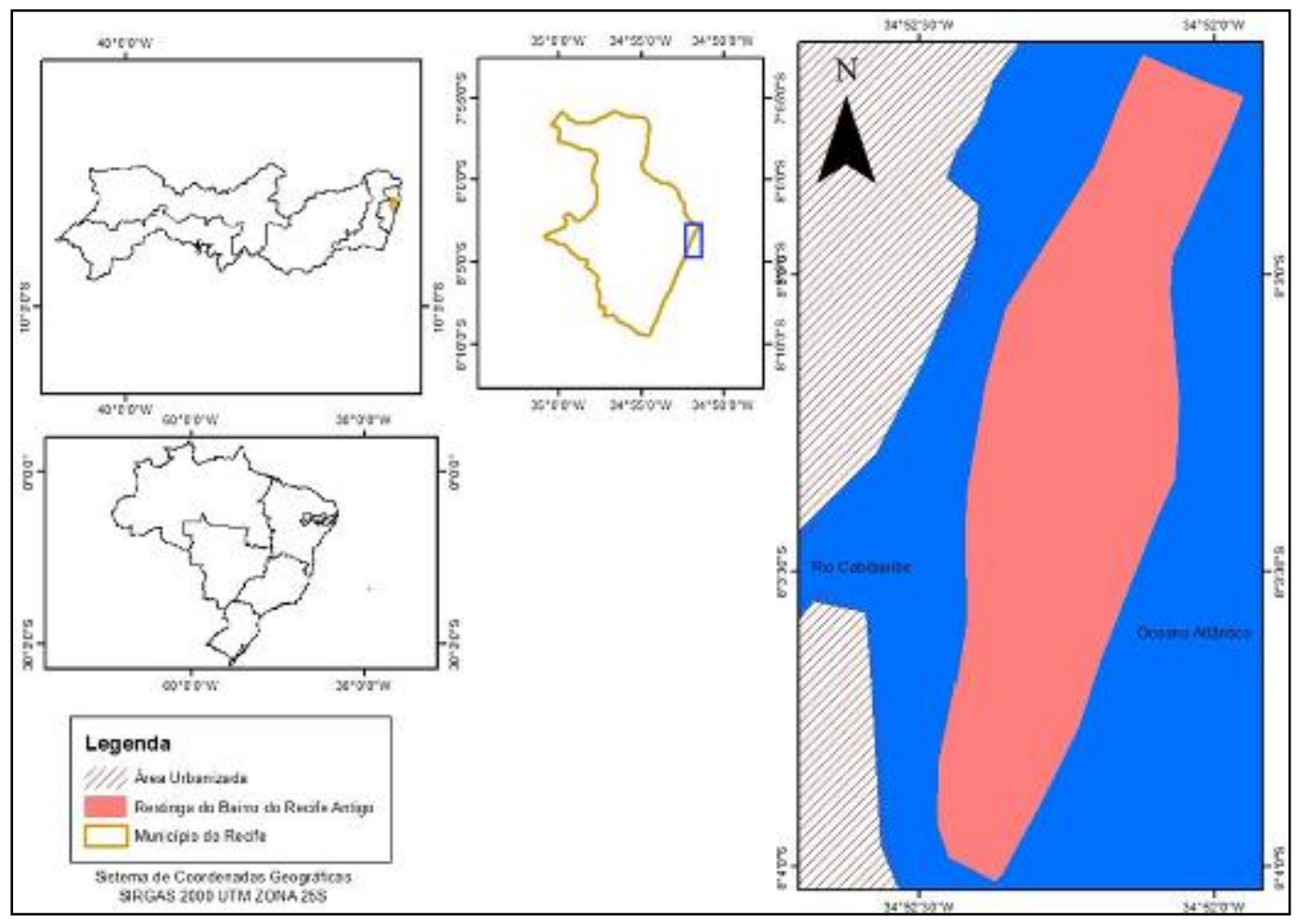

Figura 01: Localização da área de pesquisa. Fonte: $\mathrm{O}$ autor.

Posteriormente, foi realizada uma revisão bibliográfica sobre a restinga do Recife Antigo, acerca da sua localização e aspectos do meio físico presentes na atual paisagem, em concomitância 
a uma revisão dos processos naturais da gênese e desenvolvimento de uma restinga para servir de referencial para interpretar a evolução da restinga do Recife no pretérito, com ênfase para à formação geomorfológica da feição em questão. Ademais, realizamos uma revisão sobre a formação da planície do Recife fazendo uma relação entre o desenvolvimento tectônico e sedimentar da área em questão.

Ocorreram visitas a campo com a finalidade de reconhecimento da área em termos de extensão, confirmação dos dados secundários investigados anteriormente no levantamento bibliográfico e ajustes cartográficos da escala. Durante as atividades de campo foram obtidos dados primários in situ. A visita à área de estudo é imprescindível ao trabalho, aqui exposto, por causa da observação direta da paisagem, ou seja, ir à restinga do Recife Antigo contribuiu para coletar, confirmar e melhorar dos dados da pesquisa.

Em seguida houve a separação das imagens pelos séculos para trabalhar de forma cronológica. Logo, começou a verificar as mudanças na estrutura urbana da restinga século por século e dessa forma ter consciência do desenvolvimento do bairro do Recife. Frisando, quanto mais se passava os anos maiores eram a influência da espécie humana na alteração da paisagem natural. Por conseguinte, foi analisado a dinâmica da restinga no decorrer dos séculos e foi possível ver como o fator antrópico alterou completamente a ação dos agentes fluvial e marinhos.

\section{RESULTADOS E DISCUSSÃO}

A restinga do Recife Antigo passou por várias fases de expansão urbana no decorrer dos seus seis séculos levando ao espaço ter ocupação e usos distintos em um curto período de tempo. Sendo essas mudanças de utilização do solo serem conduzidas inicialmente pela intercalação entre duas potencias coloniais Portugal do século XVI até meados da primeira metade do XVII, em seguida Holanda do século XVII de 1630 a 1654 e posteriormente o domínio português novamente. Das quais moldaram a fisiografia da restinga de maneira significativa em termos de aterros e desenvolvimento do solo urbano, tendo parte desta estrutura permanecida até os dias atuais.

As transformações relacionadas ao uso e ocupação do solo permearam de maneira geral por três fases sendo elas: ocupação, invasão e transformação. A primeira consiste no tempo percorrido desde a chegada dos portugueses em 1500 até a invasão holandesa nos anos de 1630. Nesse momento histórico o objetivo dos lusitanos seria a princípio apenas extrair as riquezas das terras até então desconhecidas sem ocupá-las, porém isso só durou até os anos de 1530, haja a necessidade de ocupar efetivamente o local devido aos interesses de outras nações no Brasil. 
A ocupação no período do século XVI no Recife Antigo foi baseada em poucas construções sendo preservadas as características da dinâmica natural da restinga. Estando presente nas intervenções antrópicas no final deste século e início do XVII a edificação de forte, casas, armazéns, tavernas, prostíbulos, igreja, ancoradouro, a cruz do patrão e o porto (FIGURA 02). Frisando, a fixação ocorre na ponta do istmo uma vez desta parte conter uma área maior, visto a restinga ser muito estreita mesmo contendo aproximadamente sete quilômetros de comprimento no sentido Norte-Sul não detendo mais de um meio de largura na sua maior parte.

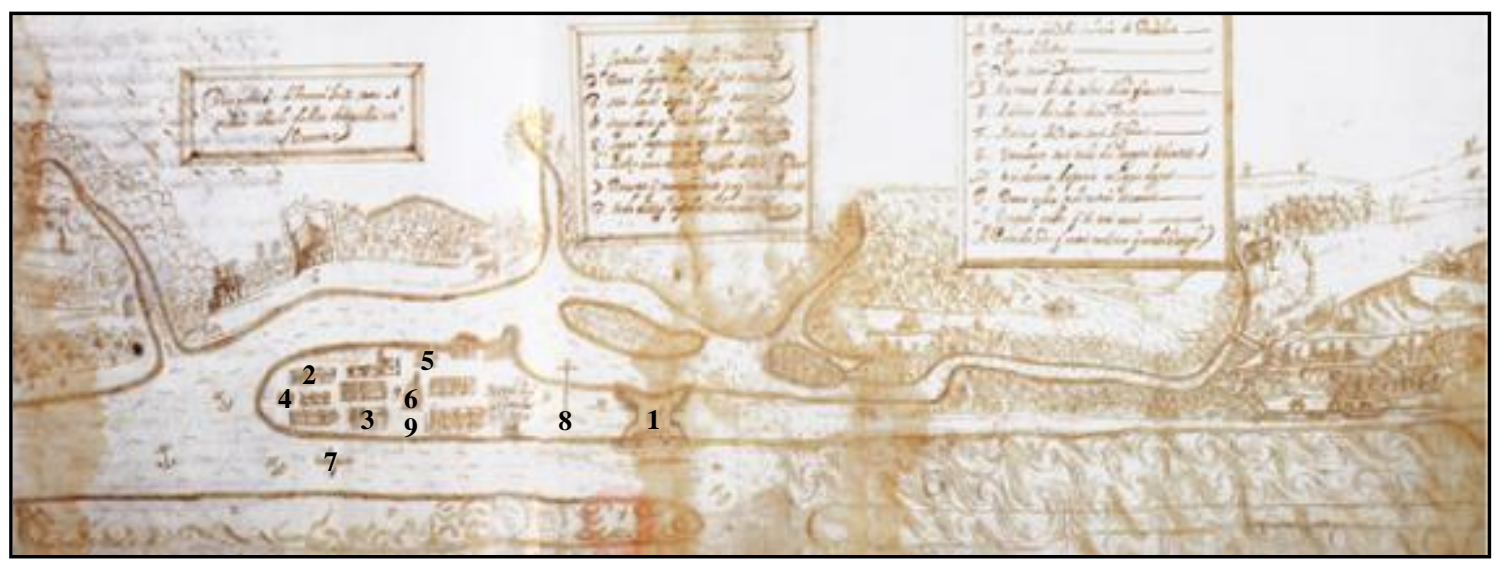

Figura 02: A ínfima e concentrada ocupação da restinga do Recife no início da povoação estando presentes a edificação de forte (1), casas (2), armazéns (3), tavernas (4), prostíbulos (5), igreja (6), ancoradouro (7), a cruz do patrão (8) e o porto (9). Fonte: CECI, 2013.

No século XVII basicamente se tem uma preservação das características naturais da restinga, visto ainda não houvesse uma necessidade em ocupação de todos os espaços pela grande quantidade de terras no continente próximas ao porto a serem ocupadas. A primeira fase, a ocupação, a restinga pode ser dividida em duas partes as terras habitadas e não habitadas. A área habitada (FIGURA 02) ficava restrita a ponta da restinga onde se detinha mais terras a ocupação e a utilização do espaço eram baseadas no comercio feito nos ancoradouros, no porto e nos armazéns e o lazer era atribuído à igreja, ao prostíbulo e a taberna. A parte não habitada (FIGURA 02) ficava o forte do Forte de São Jorge Velho tendo a função de defesa e ainda nesta porção do espaço o que prevalecia era o ambiente sem muitas transformações urbanas.

Na segunda fase tem-se a invasão, consta da ocupação dos holandeses da parte mais a Leste da capitania Pernambuco. Em necessidade de defender seu domínio recém-obtido foram erguidos na restinga dois fortes: Brum e Buraco. O conjunto desses três fortes ratifica a ideia de que a restinga nos séculos XVI e XVII teve sua importância primordial como defesa sendo o porto uma função secundaria mesmo sendo este o destino das importações e exportações praticadas em Pernambuco. 
Em meados da metade do século XVII, em 1654, os holandeses foram expulsos de Pernambuco tendo nesse momento no Bairro do Recife uma quantidade de trezentos prédios, (ALCANCE, 2013). Evidenciando já uma grande quantidade de edifícios com mais de um andar consequência essa de uma evolução urbana baseada em espaços escassos na restinga e também de um grande impulso na ocupação do recife antigo num intervalo de 24 anos de domínio holandês. Frisando a existência de outros elementos urbanos como: casas, sobrados, igreja, alfândega, cadeia, provedoria, câmara, sinagoga, armazéns e diversas ruas, (ALCANCE, 2013).

Dentre as três fases (ocupação, invasão e transformação) a terceira está relacionada as modificações relacionadas ao uso e ocupação do solo no Recife Antigo num período de tempo maior no qual vem desde o século XVIII ao XXI. Nesse intervalo o atual bairro do Recife sofre profundas transformações de âmbito na maior quantidade de aterros, construções e consumo dos espaços presentes.

Na Planta genográfica do bairro do Recife Antigo de 1749 (FIGURA 03) fica nítido uma tendência ao número de igrejas do istmo ser bem menor em comparação a Ilha de Antonio Vaz, (LOUREIRO e AMORIM, 2000). O motivo dessa configuração viria da característica do bairro no qual mesmo após a expulsão dos holandeses preserva uma particularidade comercial do que de residencial. Isso faz da restinga uma área cuja função seria o comercio onde na verdade desde a sua gênese. Portanto, mesmo o bairro do Recife ter crescido expressivamente no século XVIII possuiu uma tendência de uso comercial mesmo existindo casas, sobradados e outras edificações de cunho residencial.

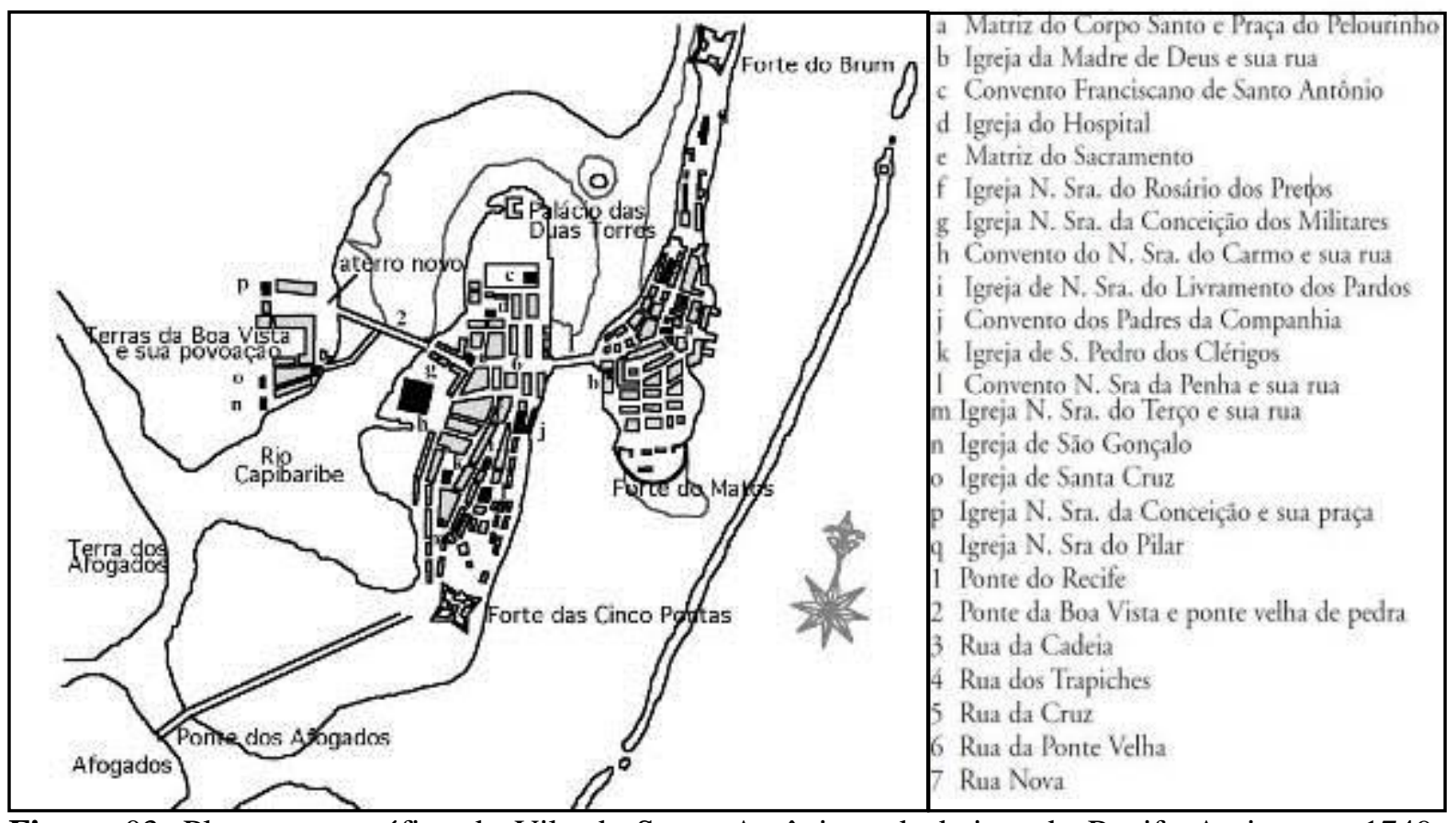

Figura 03: Planta genográfica da Vila de Santo Antônio e do bairro do Recife Antigo em 1749.

Fonte: Loureiro e Amorim, 2000. 
O bairro do Recife Antigo no século XIX passou por uma grande transformação devido à concepção de um Estado moderno visando o progresso uma vez que todo o Brasil passava também por esta concepção. Desta forma as estruturas coloniais "retrogradas" estariam atrapalhando o desenvolvimento do bairro sendo necessário mudanças urbanísticas para modernizar o mesmo. Dentre os pontos de contribuição a tais mudanças viria da chegada da Família Real no Brasil, a abertura dos portos para outras nações e as aplicações de capital da Inglaterra. Esses elementos somados fez surgir à atualização do bairro do Recife Antigo principalmente o porto que servia de ponto de exportação e importação dos produtos.

No século XIX a Restinga passa por sua primeira reforma urbana arquitetada pelo governo, sendo esta influenciada pela urbanização vivenciada pelos Franceses. Nesse contexto não foram levados da importância da preservação e conservação da riqueza histórica construída nos séculos anteriores, por isso houve destruições, modificações e criações na estrutura urbana. A título de destruição houve o derrubada da capela do Corpo Santo edificada no século XVI pelos lusitanos e os dois arcos: Conceição e Santo Antônio, no qual davam que caminho para a Ponte Maurício de Nassau.

Em 1816, foi criado Plan Of the Porto of Pernambuco (FIGURA 04) elaborado por Henry Koster, no qual evidencia os elementos presentes no porto do Recife como formas residuais da acumulação de séculos pretéritos. Dentre esses componentes destaca-se os bancos de areia (FIGURA 04) pertencentes à dinâmica existentes ainda na restinga sendo representado por espaços pontilhados. Os arrecifes emersos e submersos, o porto, os ancoradouros do poço e do Mosqueteiro, o Forte do Brum e do Buraco, a Cruz do Patrão e as áreas construídas na extremidade da restinga. (FIGURA 04). Apesar da criação desta obra icnográfica ser do século XIX evidencia pouca exatidão na constituição da urbanização presente no Recife Antigo. Uma vez neste momento histórico existir representações cartográficas mais detalhistas em termos dos espaços construídos.

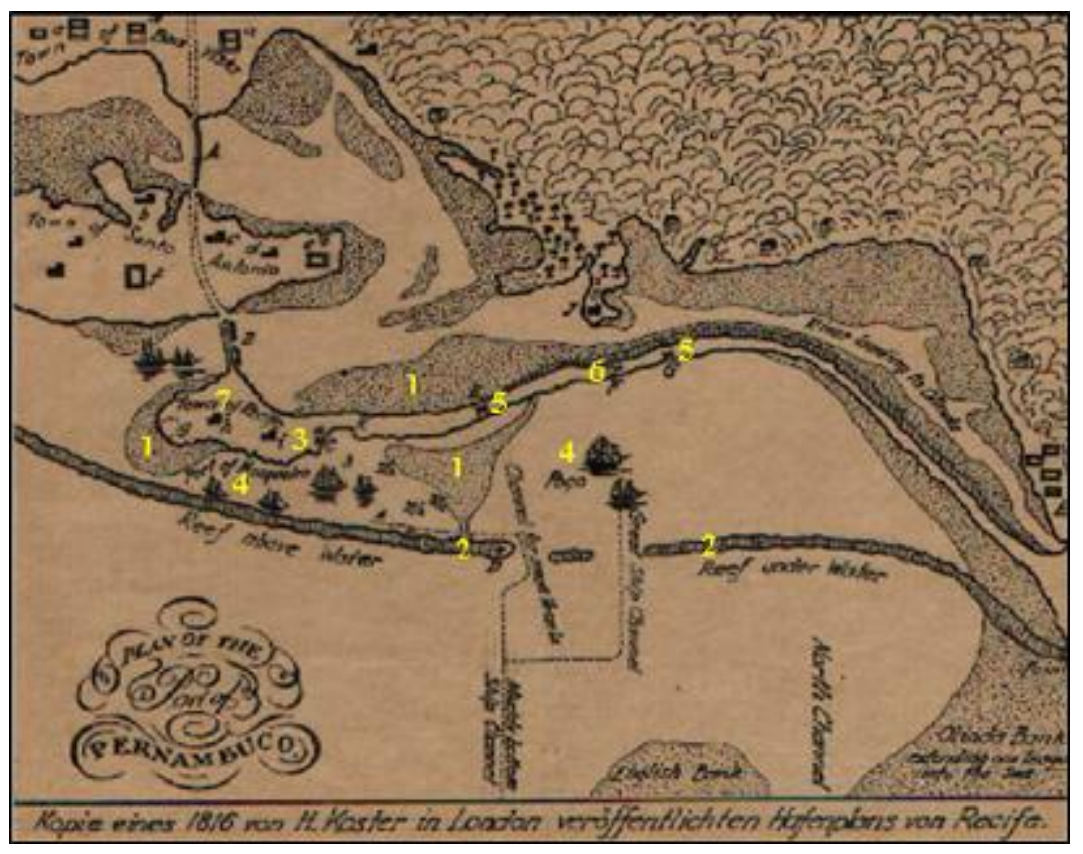


Figura 04: O Plan of the Port of Pernambuco elaborado em 1816 do Recife, constituído por: 1- bancos de areia, 2- arrecifes emersos de quantidade de aterros realizado e submersos, 3 - porto, 4 - ancoradouros do poço e do Mosqueteiro, 5 - Forte do Brum e do Buraco, 6 - Cruz do Patrão, 7 - áreas ocorria no sentid construídas. Fonte: CECI, 2013. s na foz conjunta dos rios Capibarive с neven tendo a Norte deste ficado com as características naturais da restinga devido à baixa utilização deste espaço.

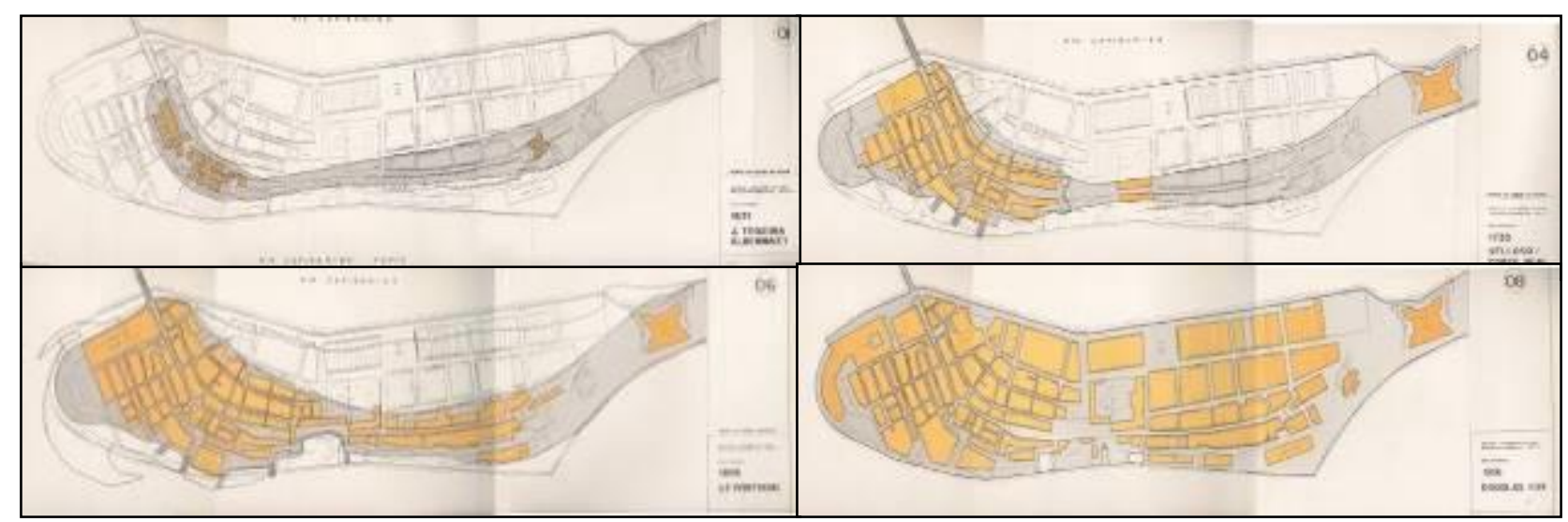

Figura 05: Cartas de escala 1:2000evidenciando a evolução urbana proveniente da acumulação tecnogênica vinda dos aterros ocorridos na restinga no decorrer dos séculos XVII, XVIII, XIX e XX. Fonte: Menezes, 1988

No início do século XX existiu um grande adensamento urbano nas áreas já construídas principalmente entre a extremidade do istmo até o forte do Brum. De acordo com a planta da Cidade do Recife de 1906 confeccionada por Douglas Fox e H. Michell Whitley entre 1912 e 1915 a restinga teve um rompimento causado pelas águas do mar por motivo das alterações no equilíbrio marinho ocasionado pela construção de um molhe nas proximidades do forte do Buraco. Desta forma percebe-se a influência antrópica alterando a dinâmica da restinga, no caso em questão da dinâmica marinha, já no início do século XX.

\section{CONSIDERAÇÕES FINAIS}

A unidade geomorfológica restinga foi bastante alterada do século XVI ao XX, com as várias intervenções antrópicas no decorrer do tempo. No século XVI e XVII houve fortes 
alterações na morfologia da restinga através dos aterros para a expansão do solo urbano. Mesmo com todas essas modificações da ocupação a dinâmica geomorfológica de âmbito natural da restinga ocorreu devido à interferência humana não ter alterado de forma significativa a ação dos agentes fluvial e marinho.

No transcorrer do período de XVIII a XXI a restinga sofreu grandes transformações na sua fisiografia pelo fato do maior adensamento das construções. Nesse intervalo de tempo o espaço do bairro do Recife Antigo recebeu mais acréscimos e área urbana aumentou de maneira horizontal (aterros) e verticalmente (prédios). Nesse contexto a unidade geomorfológica passou a ter modificações na sua dinâmica natural.

Em relação a uma modificação estrutural de cunho bastante primordial ocorrida no século XX no Recife Antigo foi o corte da restinga. Essa ruptura fez então uma separação entre a restinga tornando esta uma ilha fluvial de cunho antrópico. Logo, a restinga ficou dividida em duas partes: ao sul bastante urbanizada e a norte essencialmente composta por uma faixa de areia banhada pelo oceano, todavia com uma forte influência humana principalmente na dinâmica marinha. Atualmente, a morfodinâmica da restinga foi alterada passando a funcionar como uma ilha fluvial e não mais como restinga.

\section{REFERÊNCIAS}

ALCANCE, Longo. Bairro do Recife. Terceira versão, 2002. Disponível em: <http://www.longoalcance.com.br/brecife/navios.htm> Acessado em: 10 de janeiro de 2016. ANDRADE, M. C. Recife: problemática de uma metrópole de região subdesenvolvida. Recife: Editora Universitária / UFPE, 1979.

ASSIS, Hortência M. B.; PFALTZGRAFF, Pedro Augusto dos S. (Coordenação e Organização). Atividades impactantes sobre o meio ambiente da Região Metropolitana do Recife. In: Sistema de Informações para Gestão Territorial da Região Metropolitana do Recife. Projeto Singre II. Série Degradação Ambiental II. Recife: CPRM, 2001. 81p.

BARRETO, Ângela Maranhão. O Recife através dos Tempos: formação da sua paisagem. FUNDARPE - Recife, 1994.

CECI. Centro de Estudos Avançados da Conservação Integrada. Disponível em: http://www.cecibr.org/istmo/index.html. Acessado em: 20/02/2016.

LOUREIRO, Claudia; AMORIM, Luiz. O Mascate, o Bispo, o Juiz e os Outros: Sobre a Gênese

Morfológica do Recife. R. B. Estudos Urbanos e Regionais No 2 / outubro 2000. 
MENEZES, J. L. M. Atlas Histórico-Cartográfico do Recife. Obras e consultas/Fundação Joaquim Nabuco no 9. Ed. Massagana, 110p. 1988.

SANTOS, Leandro Diomério João dos. Evolução morfodinâmica e antropogênica da unidade geomorfológica restinga no bairro do Recife Antigo - PE. Dissertação (Mestrado) - Universidade Federal de Pernambuco. Programa de Pós-Graduação em Geografia, 2013. 